\title{
Predicting 5-fluorouracil toxicity in colorectal cancer patients from peripheral blood cell telomere length: a multivariate analysis
}

\author{
MB Garg ',2, LF Lincz ${ }^{2,3,4}$, K Adler', FE Scorgie $^{2,3}$, SP Ackland ${ }^{1,2,4}$ and JA Sakoff ${ }^{*, 1,2,4}$ \\ 'Department of Medical Oncology, Calvary Mater Newcastle Hospital, Hunter Regional Mail Centre, Locked Bag No 7, Waratah, NSW 23 I 0, Australia; \\ ${ }^{2}$ Hunter Medical Research Institute (HMRI) Cancer Research Program, Newcastle, NSW, Australia; ${ }^{3}$ Hunter Haematology Research Group, Calvary \\ Mater Newcastle Hospital, Waratah, NSW, Australia; ${ }^{4}$ The University of Newcastle, Callaghan, NSW, Australia
}

\begin{abstract}
BACKGROUND: Identifying various pretreatment factors that predict chemotherapy-induced toxicity in colorectal cancer (CRC) patients undergoing treatment for their disease is crucial to optimising patient care.

METHODS: Seventy-three patients received adjuvant 5-fluorouracil (5FU)/leucovorin using either the Mayo Clinic $(n=42)$ or a weekly schedule $(n=31)$ and evaluated for clinical toxicity. Pretreatment blood analysis included measures of plasma uracil and dihydrouracil, peripheral blood mononuclear cell (PBMNC) telomere length ( $T L)$, standard biochemistry and cell differential analysis. On the first day of treatment 5FU-pharmacokinetic variables of area under the curve, half life and clearance were also measured. These variables together with age and gender were used in univariate and multivariate analysis as predictors of clinical toxicity.

RESULTS: For the Mayo schedule the primary toxicities were neutropenia (69\%), mucositis (58\%) and leukopenia (46\%), with 70\% of patients presenting with haematological toxicity $\geqslant$ grade I (neutropenia and/or leukopenia). Multivariate analysis showed that haematological toxicity was predicted by short TL, high platelet lymphocyte ratio (PLR) and low neutrophil count $\left(R^{2}=0.38\right.$, $P<0.0006)$, whereas mucositis was predicted by age, $T L$ and $P L R\left(R^{2}=0.34, P<0.00 I\right)$. For the weekly schedule diarrhoea predominated (16\%), with female gender as the only predictive factor. Although measures of uracil metabolism correlated well with 5FU metabolism ( $r=0.45-0.49$ ), they did not indicate abnormal pyrimidine metabolism in this cohort and not surprisingly failed to predict for $5 F U$ toxicity.

CONCLUSION: Short TL of PBMNC and an increased PLR were strong predictors of mucositis and haematological toxicity in CRC patients undergoing 5FU treatment in the adjuvant setting.

British Journal of Cancer (2012) I 07, 1525-1533. doi:10.1038/bjc.2012.42I www.bjcancer.com

Published online 18 September 2012

(C) 2012 Cancer Research UK
\end{abstract}

Keywords: pharmacokinetics; telomere length; 5FU toxicity; platelet lymphocyte ratio; colorectal cancer

Defining the parameters contributing to clinical toxicity has been the subject of study by our group for several years (Gurney et al, 1998; Garg et al, 2002). Although some of the variability in toxicity is accounted for by variations in drug pharmacokinetics (PK), differences in co-morbidity (cardiac, liver or renal diseases), and predisposing factors (gender and age), a considerable proportion remains unexplained. 5-Fluorouracil (5FU) has been used as standard chemotherapy for the adjuvant treatment of colorectal cancer (CRC) for more than 50 years. Similar to many other antineoplastic agents, 5FU has a relatively narrow therapeutic window and wide inter-patient variability in toxicity. The traditional practice of normalising dose to body surface area (BSA) takes into account only two variables (height and weight). Not surprisingly, patients experience a wide range of toxicities and severities, with the primary dose-limiting complications being neutropenia, leukopenia, mucositis and diarrhoea (Tsalic et al, 2003; Patel et al, 2004). There is clearly a need for better pretreatment markers that can predict for 5FU-induced toxicity in CRC patients well in advance of their chemotherapy.

*Correspondence: Dr JA Sakoff; E-mail: jennette.sakoff@newcastle.edu.au Received I May 2012; revised 20 August 2012; accepted 29 August 2012; published online 18 September 2012
Various studies have examined 5FU PK in CRC patients and shown significant variability in 5FU area under the curve (AUC) and clearance $(\mathrm{Cl})$ of up to three-fold (Goldberg et al, 1988; Milano et al, 1994; Vokes et al, 1996; Gusella et al, 2009). Approximately $80 \%$ of $5 \mathrm{FU}$ is cleared by catabolism via dihydropyrimidine dehydrogenase (DPD) (Sommadossi et al, 1982). Variability in DPD activity can occur due to physiologic factors, organ dysfunction and genetic polymorphisms. Complete or partial familial deficiencies have also been reported (Diasio et al, 1988; Lu et al, 1993; Etienne et al, 1994; Van Kuilenburg et al, 1999). A simple marker for catabolism of 5FU and thus DPD activity before therapeutic dosing is the analysis of endogenous pyrimidine levels. As DPD catalyses the production of dihydrouracil $\left(\mathrm{UH}_{2}\right)$ and dihydrofluorouracil $\left(\mathrm{FUH}_{2}\right)$ from uracil (U) and 5FU, respectively, analysis of the endogenous $\mathrm{UH}_{2} / \mathrm{U}$ ratio has been proposed to predict 5FU catabolism and thus toxicity (Gamelin et al, 1999; Ciccolini et al, 2006).

Predicting the effect of 5FU on normal tissue, particularly of haematological origin, is important in identifying those patients most likely to experience toxicity. In this regard, our research efforts have turned towards defining the replicative capacity of bone marrow progenitors cells (Lincz et al, 2004). We have shown that the ability of stem cells to repopulate the haematopoietic system after myeloablation is dependent upon stem cell telomere length (TL) (Lincz et al, 2004). Telomeres are tandemly repeated 
hexanucleotide sequences (TTAGGG) located at the ends of linear chromosomes, which progressively become shorter with time leading to cell senescence (Rhyu, 1995; Blackburn, 2005). We have previously shown that TL of peripheral blood mononuclear cell (PBMNC) accurately reflects TL of bone marrow cells (Sakoff et al, 2002). We propose that TL of PBMNC is a marker of bone marrow replicative capacity and thus a predictor for $5 \mathrm{FU}$-induced haematopoietic toxicity.

Baseline blood parameters of neutrophil to lymphocyte ratio (NLR) and platelet lymphocyte ratio (PLR), well-known markers of systemic inflammatory response (SIR), have already been shown to be useful prognostic indicators for cancer patients. The NLR has been shown to predict for clinical benefit, progression and survival in CRC patients with metastatic disease (Chua et al, 2011a), whereas the PLR has been shown to predict for blood toxicity in patients with non-small cell lung cancer treated with paclitaxelcisplatin chemotherapy (Arrieta et al, 2010).

The aim of this study was to conduct a comprehensive survey of clinically measurable variables in order to determine the best predictors of 5FU toxicity. Although many of these variables have been investigated in separate studies (Chua et al, 2011b), few have analysed all of them in a single cohort. The present study also incorporates a unique set of biomarkers including measures of uracil catabolism, TL and SIRs, which have not previously been examined in relation to chemotherapy-induced toxicity in CRC patients.

\section{MATERIALS AND METHODS}

\section{Patient cohort}

Eligible patients had a recent diagnosis of CRC stage B or C, and were of any age, both genders, with ECOG performance status 0, no other significant medical illness and normal haematological $\left(\mathrm{Hb}>100 \mathrm{gl}^{-1}\right.$, white blood count $(\mathrm{WBC})>4.0 \times 10^{9}$ per 1 , platelets $>100 \times 10^{9}$ per 1), liver (bilirubin $<$ ULN (upper limit normal), ALT $<2 \times \mathrm{ULN}, \mathrm{ALP}<2 \times \mathrm{ULN}$ ) and renal function (creatinine $>130 \mathrm{mmoll}^{-1}$ ). Written informed consent was obtained from all participants and the research was approved by the Hunter Area Health Research Ethics Committee. Patient recruitment was between year 2001-2004. Patients were given 5FU and folinic acid (leucovorin, LV) for 6 months by either the Mayo Clinic schedule (5FU $425 \mathrm{mg} \mathrm{m}^{-2}$ and LV $20 \mathrm{mg} \mathrm{m}^{-2}$ daily for 5 days every 4 weeks) or a weekly schedule (5FU $500 \mathrm{mg} \mathrm{m}^{-2}$ and LV $20 \mathrm{mg} \mathrm{m}^{-2}$ weekly for 4 weeks). 5-Fluorouracil was given over 5-10 min after a bolus of LV.

\section{Blood samples}

Baseline blood samples were collected on the day (time range 8:45-16:00 hours) before 5FU/LV administration, for measurement of PBMNC TL (EDTA, $4 \mathrm{ml}$ ), $\mathrm{U}$ and $\mathrm{UH}_{2}$ (lithium heparin, $5 \mathrm{ml}$ ). Post-treatment blood samples were collected at $10 \mathrm{~min}, 30 \mathrm{~min}$, $45 \mathrm{~min}$ and $60 \mathrm{~min}$ after $5 \mathrm{FU}$ administration, for measures of 5FU and $\mathrm{FUH}_{2}$ (lithium heparin, $5 \mathrm{ml}$ ). Blood was also collected before treatment and at the end of the first month for blood biochemistry analysis, and twice weekly for the first month for a complete blood count and differential using Hunter Area Pathology Service, NSW, Australia. Non-treated blood plasma samples were purchased from the Red Cross and used as controls and standards for the highperformance liquid chromatography (HPLC) assays.

\section{Clinical toxicity}

Patients were evaluated clinically for toxicity before starting chemotherapy and weekly during the first month. Clinical toxicity data was categorised by using Standard NCI CTC ver2.0 criteria and included four gradings for each of thrombocytopenia, leukopenia, neutropenia, febrile neutropenia, mucositis and diarrhoea. Haematological toxicity ( $\geqslant$ grade 1 ) was defined as the existence of at least one toxicity of grade 1 or greater in the categories of leukopenia or neutropenia. A complete blood count and differential was performed twice weekly for the first month. Electrolytes, urea, creatinine and liver function tests (bilirubin, AST, ALT, Albumin, LDH) were performed before treatment and at the end of the first month.

\section{5-Fluorouracil pharmacokinetics}

Plasma from the baseline blood sample and $10 \mathrm{~min}, 30 \mathrm{~min}, 45 \mathrm{~min}$ and $60 \mathrm{~min}$ after the first infusion of $5 \mathrm{FU} / \mathrm{LV}$, was analysed for $5 \mathrm{FU}$ and $\mathrm{FUH}_{2}$ concentration by HPLC with variable UV detection using our previously published method (Ackland et al, 1997). Plasma standards in the concentration range of $0.20-20 \mu$ mole $^{-1}$, were prepared by adding aqueous stock standards to pooled human plasma. The concentration of $5 \mathrm{FU}$ and $\mathrm{FUH}_{2}$ in patient samples and quality control samples was determined from the calibration curves. Plasma 5FU and $\mathrm{FUH}_{2}$ concentration values at four time points after the first dose were used to calculate various PK variables including the area under the time/concentration curve (AUC), total body $\mathrm{Cl}$ and terminal half life $\left(\mathrm{T}_{1 / 2}\right)$ using a non-compartmental model, WinNonlin (v 5.0). All blood samples were processed within $10 \mathrm{~min}$ of venipuncture. We have previously shown no degradation of 5FU using this methodology (Ackland et al, 1997).

\section{Uracil catabolism}

Plasma from the baseline blood sample was analysed for $U$ and $\mathrm{UH}_{2}$ concentration by HPLC with variable UV detection using our previously published method (Garg et al, 2002). Plasma standards in the concentration range of $0.02-5.0 \mu \mathrm{molel}^{-1}$, were prepared by adding aqueous stock standards to double-dialysed ( $\mathrm{U}$ and $\mathrm{UH}_{2}-$ free) pooled human plasma. The concentration of $U$ and $\mathrm{UH}_{2}$ in patient samples and quality control samples was determined from the calibration curves.

\section{Telomere length}

Measures of PBMNC TL were used to predict bone marrow replicative capacity (Sakoff et al, 2002). Peripheral blood mononuclear cells were separated from fresh whole blood, genomic DNA was extracted using the mini salt extraction method (Miller et al, 1988) and analysed for TL by our previously described method (Sakoff et al, 2002) involving DNA enzymatic digestion and Southern blotting. For each sample, the average of two mean TLs calculated from two separate blots was used for statistical analysis.

\section{Statistical analysis}

Data collected included demographic, clinical toxicity, complete blood count and differential, biochemistry panel, 5FU PK variables, measures of plasma $\mathrm{U}$ and $\mathrm{UH}_{2}$, and $\mathrm{TL}$ analysis. All data that failed normality was appropriately transformed (log or sqrt) before statistical analysis. All toxicity data was categorised by standard NCI CTC ver 2.0 criteria and treated as ordinal categorical or binomial variables as indicated. Differences between cohorts were determined by student's $t$-test and linear correlations were assessed by Pearson correlation coefficient, univariate analysis was performed by linear regression and only variables with $P$-values $<0.25$ were included in subsequent multivariate models. For multivariate analysis, backward stepwise regression with casewise deletion was used to determine those variables significantly contributing to each of the respective toxicity outcomes. Statistica (StatSoft, Tulsa, OK, USA) v 6.0 programme was used for statistical analysis. $P$-values $<0.05$ were considered statistically significant. 


\section{RESULTS}

\section{Baseline characteristics}

Seventy-three CRC patients (median age 63 years; range 34-82 years; 42 males; 31 females; 11 stage $B, 62$ stage $C$ ) received adjuvant 5FU/LV with either the Mayo Clinic schedule $(n=42)$ or weekly schedule $(n=31)$ according to clinician preference (Table 1). The two groups showed a similar age and gender distribution. There were no differences between the two patient cohorts in terms of BSA, AST, albumin, bilirubin and creatinine. No underlying clinical predisposition in terms of liver and renal function was identified in either group. Baseline WBC, absolute neutrophil count (ANC) and platelets were within normal limits

Table I Patient characteristics and toxicity by 5FU treatment regimen

\begin{tabular}{|c|c|c|}
\hline & \multicolumn{2}{|c|}{ Treatment regimen } \\
\hline & $\begin{array}{l}\text { Mayo daily schedule } \\
\qquad n=42\end{array}$ & $\begin{array}{c}\text { Weekly schedule } \\
n=31\end{array}$ \\
\hline $\begin{array}{l}5 F U\left(\mathrm{mg} \mathrm{m}^{-2}\right) \\
\text { LV }\left(\mathrm{mgm}^{-2}\right) \\
\text { Schedule }\end{array}$ & $\begin{array}{c}425 \\
20 \\
\text { Daily for } 5 \text { days every } 4 \text { weeks }\end{array}$ & $\begin{array}{c}500 \\
20 \\
\text { Weekly for } 4 \text { weeks }\end{array}$ \\
\hline $\begin{array}{l}\text { Gender, n (\%) } \\
\text { Male } \\
\text { Female }\end{array}$ & $\begin{array}{l}24(57) \\
18(43)\end{array}$ & $\begin{array}{l}18(58) \\
13(42)\end{array}$ \\
\hline Age (years) & $62(58-66)$ & $64(54-72)$ \\
\hline $\begin{array}{l}\text { CRC, } \mathrm{n}(\%) \\
\text { Stage B } \\
\text { Stage C }\end{array}$ & $\begin{array}{r}5(12) \\
37(88)\end{array}$ & $\begin{array}{r}6(19) \\
25(81)\end{array}$ \\
\hline $\begin{array}{l}\text { Platelet nadir }\left(10^{9} 1^{-1}\right) \\
\text { WBC nadir }\left(\left.10^{9}\right|^{-1}\right) \\
\text { ANC nadir }\left(10^{9} 1^{-1}\right)\end{array}$ & $\begin{aligned} 231 & (196-269) \\
3.7 & (2.6-4.7) \\
0.7 & (0.3-2.0)\end{aligned}$ & $\begin{aligned} 236 & (215-258) \\
4.8 & (4.1-6.4) \\
2.6 & (1.7-3.7)\end{aligned}$ \\
\hline $\begin{array}{l}\text { Thrombocytopenia, n (\%) } \\
\text { Grade } 4\end{array}$ & I (2) & $0(0)$ \\
\hline $\begin{array}{l}\text { Leukopenia, n (\%) } \\
\text { Grade I } \\
\text { Grade } 2 \\
\text { Grade } 3 \\
\text { Grade } 4\end{array}$ & $\begin{aligned} & 4(10) \\
11 & (27) \\
3 & (7) \\
1 & (2)\end{aligned}$ & $\begin{array}{l}3(10) \\
1(3) \\
1(3) \\
0(0)\end{array}$ \\
\hline $\begin{array}{l}\text { Neutropenia, n (\%) } \\
\text { Grade I } \\
\text { Grade } 2 \\
\text { Grade } 3 \\
\text { Grade } 4\end{array}$ & $\begin{aligned} & 2(5) \\
5 & (12) \\
8 & (20) \\
13 & (32)\end{aligned}$ & $\begin{array}{l}6(19) \\
2(6) \\
1(3) \\
0(0)\end{array}$ \\
\hline $\begin{array}{l}\text { Haematological toxicity } \\
\quad \geqslant \text { Gradel }\end{array}$ & $29(70)$ & $10(32)$ \\
\hline $\begin{array}{l}\text { Febrile neutropenia, n (\%) } \\
\text { Grade } 3 \\
\text { Grade } 4\end{array}$ & $\begin{array}{l}1(2) \\
2(5)\end{array}$ & $\begin{array}{l}\text { I (3) } \\
0(0)\end{array}$ \\
\hline $\begin{array}{c}\text { Mucositis, n (\%) } \\
\text { Grade I } \\
\text { Grade } 2 \\
\text { Grade } 3\end{array}$ & $\begin{array}{r}4(10) \\
15(36) \\
5(12)\end{array}$ & $\begin{array}{l}2(6) \\
2(6) \\
0(0)\end{array}$ \\
\hline $\begin{array}{l}\text { Diarrhoea, n (\%) } \\
\text { Grade I } \\
\text { Grade } 2 \\
\text { Grade } 3\end{array}$ & $\begin{aligned} 17(40) \\
3(7) \\
2(5)\end{aligned}$ & $\begin{array}{l}8(26) \\
3(10) \\
2(6)\end{array}$ \\
\hline
\end{tabular}

Abbreviations: $5 \mathrm{FU}=5$-Fluorouracil; $\mathrm{ANC}=$ absolute neutrophil count; $\mathrm{CRC}=$ colorectal cancer; $\mathrm{LV}=$ leucovorin; $\mathrm{WBC}=$ white blood count. Values for non categorical data are median (lower-upper quartile) with no differences between the patient populations. No differences were observed in NLR and PLR between the two cohorts. The number of patients with NLR $\geqslant 5$ was 4 out of 42 and 2 out of 31 , whereas 18 out of 42 and 13 out of 31 patients presented with PLR $\geqslant 150$ in the Mayo and weekly cohorts, respectively. Telomere length (median) was slightly longer in the Mayo population of patients than in weekly patients although not statistically significant (Table 2).

\section{Clinical toxicities}

The overall clinical toxicity was greater in the Mayo daily schedule compared with the weekly schedule, but with differences in type of side-effect. The primary toxicities ( $\geqslant$ grade 2 ) for the Mayo schedule were neutropenia $(26(63 \%))$, mucositis $(20(48 \%))$ and leukopenia $(15(37 \%))$, whereas the predominant toxicity ( $\geqslant$ grade 2$)$ for the weekly schedule was diarrhoea (5 (16\%)). Indeed, $70 \%$ of patients receiving the Mayo schedule presented with grade 1 or greater haematological toxicity (leukopenia and/or neutropenia) compared with $32 \%$ of patients receiving the weekly schedule. Following treatment, 21 patients on the Mayo schedule had an ANC nadir $<1 \times 10^{9}$ per 1 , while only one patient observed ANC nadir $<1 \times 10^{9}$ per 1 with the weekly schedule. A total of seven patients were admitted to hospital for management of toxicity (one with isolated neutropenic fever/sepsis, two with neutropenia and mucositis, two with neutropenia and diarrhoea, one with diarrhoea and mucositis and one with isolated diarrhoea).

\section{5-Fluorouracil pharmacokinetics and endogenous pyrimidine catabolism}

5-Fluorouracil pharmacokinetic data after the first dose of 5FU including 5FU AUC $\left(\mu\right.$ mole $\left.^{-1} \mathrm{~h}^{-1}\right), 5 \mathrm{FU} \mathrm{Cl}\left(\mathrm{l}^{-1} \mathrm{~h}^{-1}\right)$, terminal half life $\mathrm{T}_{1 / 2}(\mathrm{~h})$, and AUC values for its metabolite $\mathrm{FUH}_{2}$, are detailed in Table 2 for each treatment schedule together with various baseline blood parameters. The 5FU AUC was significantly lower for the Mayo schedule than the weekly schedule primarily as a consequence of a lower administrated dose (425 vs $500 \mathrm{mg}$ ) (Table 2). The Mayo schedule showed a shorter half life $(0.16 \mathrm{vs}$ $0.20)$, a greater $\mathrm{Cl}\left(148\right.$ vs 105) and a higher $5 \mathrm{FUH}_{2} \mathrm{AUC}(32$ vs 24) than the weekly schedule, indicating greater catabolism efficiency; however, these differences were not statistically significant.

In an effort to predict for 5FU catabolism, endogenous pyrimidine catabolism was examined for each treatment schedule via measurements of $\mathrm{U}$ and $\mathrm{UH}_{2}$. No significant differences were observed between the patient cohorts. Comparisons between 5FU catabolic parameters $\left(5 \mathrm{FU} \mathrm{T} \mathrm{T}_{1 / 2}, 5 \mathrm{FU} \mathrm{Cl}\right.$ and $\left.5 \mathrm{FUH}_{2} \mathrm{AUC}\right)$ and uracil catabolic parameters $\left(\mathrm{UH}_{2}\right.$ and $\left.\mathrm{UH}_{2} / \mathrm{U}\right)$ (see Table 3 ) showed that $\mathrm{UH}_{2}$ significantly correlated and predicted for $5 \mathrm{FUH}_{2}$ AUC using either the Mayo or weekly schedule. The ratio of $\mathrm{UH}_{2} / \mathrm{U}$ also significantly predicted for $5 \mathrm{FUH}_{2}$ AUC for the Mayo schedule and predicted for $5 \mathrm{FU} \mathrm{T}_{1 / 2}$ for the weekly schedule.

\section{Univariate analysis}

Univariate analysis was performed for all grades of leukopenia and neutropenia, as well as overall haematological toxicity ( $\geqslant$ grade 1 ) and mucositis for the Mayo schedule and diarrhoea for the weekly schedule as these were the primary toxicities for each treatment regimen. The pharmacokinetic and pharmacodynamic variables used in the analysis and the correlation statistics are shown in Table 4. Leukopenia and neutropenia significantly correlated with the pharmacokinetic parameters, BSA, 5FU AUC, $5 \mathrm{FU} \mathrm{T}_{1 / 2}$ and $5 \mathrm{FU} \mathrm{Cl}$, thus the greater the $5 \mathrm{FU}$ exposure the greater the toxicity. Moreover, leukopenia and neutropenia inversely correlated with PBMNC TL. A significant association was also observed between the induction of leukopenia and increased baseline platelet and decreased lymphocyte counts. This in turn produced a significant 
Table 2 PK and PD parameters by 5FU treatment regimen

\section{Treatment regimen}

Mayo daily schedule Weekly schedule

n n

\begin{tabular}{|c|c|c|}
\hline$s$ & & \\
\hline BSA $\left(m^{2}\right)$ & 42 & $1.92(1.76-2.05)$ \\
\hline 5FU AUC $\left(\mu \mathrm{moll} \mathrm{I}^{-1} \mathrm{~h}^{-1}\right)$ & 39 & $4 \mid(3 \mid-49)$ \\
\hline $5 F \cup T_{1 / 2}(h)$ & 39 & $0.16(0.14-0.20)$ \\
\hline $5 F U C l\left(\mathrm{lh}^{-1}\right)$ & 39 & $148(107-202)$ \\
\hline $5 \mathrm{FUH}{ }_{2} \mathrm{~A} \cup \mathrm{C}\left(\mu \mathrm{moll}^{-1} \mathrm{~h}^{-1}\right)$ & 39 & $9-4 \mid)$ \\
\hline$\cup\left(\mu\right.$ mole $\left.^{-1}\right)$ & 39 & $.08-0.16)$ \\
\hline $\mathrm{UH}_{2}\left(\mu\right.$ mole $\left.^{-1}\right)$ & 38 & $5-1.86)$ \\
\hline $1 H^{\prime}$ & 38 & $10.6(6.6-15.7)$ \\
\hline A & 41 & 22( \\
\hline Album & 42 & $37(35-39)$ \\
\hline Bilirubin $\left(\mu \mathrm{mol} \mathrm{I}^{-1}\right)$ & 42 & II (7-14) \\
\hline Creatinine $\left(\mathrm{mmol} \mathrm{I}^{-}\right.$ & 42 & $75(66-86)$ \\
\hline
\end{tabular}

Pharmacodynamics

WBC $\times\left(10^{9} 1^{-1}\right)$

Platelet $\times\left(10^{9} \mathrm{I}^{-1}\right)$

ANC $\times\left(10^{9} 1^{-1}\right)$

Lymphocyte $\times\left(\left.10^{9}\right|^{-1}\right)$

NLR

PLR

Telomere length $(k b)$

\section{$31 \quad 1.93(1.73-2.10)$ \\ $28 \quad 62(46-84) *$ \\ $280.20(0.15-0.26)$ \\ $28 \quad 105(70-160)$ \\ $28 \quad 24(16-38)$ \\ $290.11(0.08-0.16)$ \\ $290.97(0.62-1.45)$ \\ $29 \quad 9.5(5.1-13.1)$ \\ $29 \quad 21(18-29)$ \\ $2938(34-40)$ \\ $29 \quad 10(8-13)$ \\ $30 \quad 80(68-89)$}

Abbreviations: $5 \mathrm{FU}=5$-fluorouracil; $\mathrm{ANC}=$ absolute neutrophil count; $\mathrm{AUC}=$ area under the curve; $\mathrm{BSA}=$ body surface area; $\mathrm{FUH}_{2}=$ dihydrofluorouracil; $\mathrm{NLR}=$ neutrophil to lymphocyte ratio; $\mathrm{PD}=$ pharmacodynamics; $\mathrm{PK}=$ pharmacokinetics; $\mathrm{PLR}=$ platelet lymphocyte ratio; $\mathrm{U}=$ uracil; $\mathrm{UH}_{2}=$ dihydrouracil; $\mathrm{WBC}=$ white blood count. Values for non categorical data are median (lower-upper quartile). * Significantly different between Mayo and weekly schedule $P<0.01$.

Table 3 Correlation $(r)$ between uracil catabolism and 5FU catabolism by $5 \mathrm{FU}$ treatment regimen

\begin{tabular}{|c|c|c|c|c|}
\hline & \multicolumn{4}{|c|}{ Treatment regimen } \\
\hline & \multicolumn{2}{|c|}{$\begin{array}{l}\text { Mayo daily schedule } \\
\qquad n=38\end{array}$} & \multicolumn{2}{|c|}{$\begin{array}{l}\text { Weekly schedule } \\
\qquad n=27\end{array}$} \\
\hline & $\mathbf{U H}_{2}$ & $\mathrm{UH}_{2} / \mathbf{U}$ & $\mathbf{U H}_{2}$ & $\mathbf{U H}_{2} / \mathbf{U}$ \\
\hline $\begin{array}{l}5 \mathrm{FU} \mathrm{T}_{1 / 2} \\
5 \mathrm{FU} \mathrm{Cl} \\
5 \mathrm{FUH}_{2} \mathrm{AUC}\end{array}$ & $\begin{array}{l}-0.164 \\
0.201 \\
0.493 * *\end{array}$ & $\begin{array}{l}-0.098 \\
-0.045 \\
0.449 * *\end{array}$ & $\begin{array}{l}-0.206 \\
0.023 \\
0.481 * *\end{array}$ & $\begin{array}{c}-0.381 * \\
0.101 \\
0.153\end{array}$ \\
\hline
\end{tabular}

Abbreviations: $5 \mathrm{FU}=5$-fluorouracil; $\quad \mathrm{AUC}=$ area under the curve; $\mathrm{FUH}_{2}=$ dihydrofluorouracil; $U=$ uracil; $U \mathrm{H}_{2}=$ dihydrouracil. $* P<0.05$, $* * P<0.0$ I.

positive association with leukopenia and PLR. Haematological toxicity ( $\geqslant$ grade 1 ) was significantly associated with 5FU AUC, $5 \mathrm{FU} \mathrm{T}_{1 / 2}, 5 \mathrm{FU} \mathrm{Cl}$, moreover, the baseline variables of $\mathrm{WBC}$, ANC and TL also showed significant associations. The presence of mucositis in this patient cohort significantly correlated with younger age and an increase in PLR. The primary toxicity induced by the weekly schedule of 5FU treatment was diarrhoea and this was only associated with gender, with females presenting with greater toxicity than males in this cohort.

Collectively, the pretreatment variables BSA, PLR, age, WBC, ANC and TL at baseline were associated with increased toxicity in the Mayo cohort of patients. The strongest association for these parameters and toxicity in this cohort are shown in Figure 1. The data clearly show that a low BSA and a high PLR is associated with increased toxicity (leukopenia data shown), whereas young patients particularly those under the age of $52(n=4)$ presented with high-grade mucositis ( $\geqslant$ grade 2 ). Furthermore, a baseline WBC, ANC and TL less than the median for the population significantly is associated with an increased incidence of haematological toxicity. Indeed, $95 \%$ of patients with a TL less than the median ( $9525 \mathrm{bp}, n=33$ ) presented with haematological toxicity ( $\geqslant$ grade 1 ) equating to a 14 -fold increased odds $(95 \%$ CI: $1.3-669, P=0.013)$. In order to gauge the magnitude of these effects on high grades of haematological toxicity, those patients with $\geqslant$ grade 3 toxicity have been highlighted in Figures 1D-F. Clearly, these responses hold true for the higher grades of toxicity, as patients with a TL less than the median had a 12.6-fold increased odds of suffering $\geqslant$ grade 3 toxicity compared with having no toxicity (95\% CI: $1.1-607, P=0.019$ ).

\section{Multivariate analysis}

Multivariate analysis was performed using independent variables of leukopenia, neutropenia, haematological ( $\geqslant$ grade 1 ) and mucositis for the Mayo daily schedule and diarrhoea for the weekly schedule (see Table 5). For each toxicity, a posttreatment and pretreatment model was generated using only those independent variables with a univariate association of $P<0.25$ (as shown in Table 4). The posttreatment model included all of the pharmacokinetic variables for $5 \mathrm{FU}$ and excluded the uracil variables, whereas the predictive model utilised the pretreatment uracil parameters and excluded the posttreatment $5 \mathrm{FU}$ parameters (AUC, $\mathrm{T}_{1 / 2}$ and $\mathrm{Cl}$ ).

For the Mayo daily schedule, all posttreatment models retained one pharmacokinetic variable for $5 \mathrm{FU}$ and were stronger predictors of haematological toxicities than their pretreatment counterparts, accounting for $32-56 \%$ of the variability. In contrast, the predictive models did not retain any of the pretreatment uracil parameters, but all contained TL and PLR (except neutropenia) and predicted $26-38 \%$ of the variability in toxicities. Only mucositis was better predicted by the pretreatment model $(34 \%$ vs $33 \%)$.

For the weekly schedule, female gender remained the only significant predictor of diarrhoea in both pre- and posttreatment models.

\section{Post-hoc analysis}

As TL is often used to define biological aging, we chose to compare TL with chronological age in our patient cohorts. The results of our analysis did not show a correlation between age and PBMNC TL. We also conducted comparisons between PLR and NLR with albumin and BSA as SIRs are often related to overall nutritional status particularly malnutrition. The results did show a significant association between PLR and albumin $\left(R^{2}=-0.439, P=0.004\right)$ and BSA $\left(R^{2}=-0.518, P<0.001\right)$, but not between NLR and albumin or NLR and BSA. In order to further clarify the role of PLR in predicting clinical toxicity we also compared the relationship of PLR with the various 5FU PK variables and no significant association was observed.

\section{DISCUSSION}

In the present study a multifactorial approach was utilised to determine the predictive capability of numerous pharmacokinetic and pharmacodynamic parameters in response to $5 \mathrm{FU}$ chemotherapy in CRC patients undergoing either the Mayo Clinic or a weekly schedule of treatment. Although numerous studies have measured various baseline characteristics as a means of predicting $5 \mathrm{FU}$ toxicity (reviewed in Chua et al, 2011b), the present study identified 5FU PK, PBMNC TL and PLR as strong predictors of blood toxicity and mucositis. 
Table 4 Univariate association between treatment-related toxicity vs PK and PD variables by 5FU treatment regimen

Treatment schedule

\begin{tabular}{|c|c|c|c|c|c|c|c|c|c|c|}
\hline \multirow[b]{3}{*}{ Variables } & \multicolumn{8}{|c|}{ Mayo daily schedule } & \multirow{2}{*}{\multicolumn{2}{|c|}{$\begin{array}{c}\text { Weekly schedule } \\
\text { Diarrhoea }\end{array}$}} \\
\hline & \multicolumn{2}{|c|}{ Leukopenia } & \multicolumn{2}{|c|}{ Neutropenia } & \multicolumn{2}{|c|}{ Haematological } & \multicolumn{2}{|c|}{ Mucositis } & & \\
\hline & $n$ & $r$ & n & $r$ & $n$ & $r$ & $n$ & $r$ & $n$ & $r$ \\
\hline \multicolumn{11}{|c|}{ Pharmacokinetics (pretreatment) } \\
\hline Age & 41 & 0.079 & 41 & 0.001 & 41 & -0.058 & 42 & $-0.366^{*}$ & 31 & 0.032 \\
\hline Gender & 41 & 0.157 & 41 & 0.148 & 41 & 0.137 & 42 & 0.003 & 31 & $0.553 * * * *$ \\
\hline BSA & 41 & $-0.397 * *$ & 41 & $-0.368 *$ & 41 & -0.253 & 42 & -0.265 & 31 & -0.263 \\
\hline$\cup$ & 38 & 0.017 & 38 & -0.087 & 38 & -0.086 & 39 & 0.138 & 29 & 0.098 \\
\hline $\mathrm{UH}_{2}$ & 37 & -0.211 & 37 & 0.025 & 37 & -0.094 & 38 & 0.025 & 29 & 0.054 \\
\hline $\mathrm{UH}_{2} / \mathrm{U}$ & 37 & -0.140 & 37 & 0.086 & 37 & 0.011 & 38 & -0.041 & 29 & -0.062 \\
\hline AST & 40 & 0.054 & 40 & 0.206 & 40 & 0.165 & 41 & 0.083 & 29 & 0.187 \\
\hline Albumin & 41 & -0.132 & 41 & -0.062 & 41 & -0.087 & 42 & -0.170 & 29 & -0.345 \\
\hline Bilirubin & 41 & -0.044 & 41 & 0.036 & 41 & 0.006 & 42 & 0.080 & 29 & -0.314 \\
\hline Creatinine & 41 & -0.038 & 41 & -0.064 & 41 & -0.096 & 42 & 0.047 & 30 & -0.171 \\
\hline \multicolumn{11}{|c|}{ Pharmacokinetcs (posttreatment) } \\
\hline 5FU AUC & 38 & $0.461 * *$ & 38 & $0.448 * *$ & 38 & $0.385^{*}$ & 39 & 0.162 & 28 & 0.151 \\
\hline $5 F U T_{1 / 2}$ & 38 & $0.624 * * *$ & 38 & $0.496 * *$ & 38 & $0.44 \mid * *$ & 39 & 0.256 & 28 & 0.209 \\
\hline $5 F U C L$ & 38 & $-0.502 * * * *$ & 38 & $-0.463 * *$ & 38 & $-0.376^{*}$ & 39 & -0.196 & 28 & -0.231 \\
\hline $5 \mathrm{FUH}_{2} \mathrm{AUC}$ & 38 & 0.012 & 38 & 0.089 & 38 & -0.136 & 39 & -0.203 & 28 & 0.149 \\
\hline 5FU TOTAL & 41 & -0.268 & 41 & -0.206 & 41 & -0.123 & 42 & -0.154 & 31 & -0.200 \\
\hline \multicolumn{11}{|c|}{ Pharmacodynamics (pretreatment) } \\
\hline WBC & 41 & -0.245 & 41 & -0.281 & 41 & $-0.426 * *$ & 42 & -0.278 & 31 & -0.153 \\
\hline Platelet & 41 & $0.328 *$ & 41 & 0.275 & 41 & 0.165 & 42 & 0.155 & 31 & -0.113 \\
\hline ANC & 41 & -0.109 & 41 & -0.255 & 41 & $-0.406^{* *}$ & 42 & -0.137 & 31 & -0.092 \\
\hline Lymphocyte & 41 & $-0.332 *$ & 41 & -0.107 & 41 & -0.072 & 42 & -0.290 & 31 & -0.198 \\
\hline NLR & 41 & 0.224 & 41 & 0.025 & 41 & -0.057 & 42 & 0.148 & 31 & 0.062 \\
\hline PLR & 41 & $0.429 * *$ & 41 & 0.247 & 41 & 0.189 & 42 & $0.311 *$ & 31 & 0.073 \\
\hline $\mathrm{TL}$ & 33 & $-0.468 * *$ & 33 & $-0.438 *$ & 33 & $-0.50 I^{* * *}$ & 34 & -0.330 & 29 & 0.076 \\
\hline
\end{tabular}

Abbreviations: $5 F U=5$-fluorouracil; $A N C=$ absolute neutrophil count; $A \cup C=$ area under the curve; $B S A=$ body surface area; NLR = neutrophil to lymphocyte ratio; $\mathrm{PD}=$ pharmacodynamics; $\mathrm{PK}=$ pharmacokinetics; $\mathrm{PLR}=$ platelet lymphocyte ratio; $\mathrm{TL}=$ telomere length; WBC $=$ white blood count. $* P<0.05$, $* * P<0.0$ I, *** $P<0.00$ I.

The observed clinical toxicity profiles were consistent with those reported in other patient cohorts with the Mayo schedule inducing significantly greater toxicity than the weekly schedule (Tsalic et al, 2003; Patel et al, 2004). The more aggressive Mayo therapy was characterised by a greater incidence of neutropenia, leukopenia and mucositis, whereas the principal toxicity in the less aggressive weekly schedule was diarrhoea. Although the weekly schedule produced less toxicity, the inclusion of this cohort still provided valid information in predicting for 5FU-induced toxicity. The study allowed us to compare the effect of low (weekly schedule) $v s$ high toxicity (Mayo).

The results clearly show that $5 \mathrm{FU}$ pharmacokinetic parameters of AUC, $\mathrm{T}_{1 / 2}$ and $\mathrm{Cl}$ predicted strongly for leukopenia, neutropenia and overall haematological toxicity, using univariate analysis in the Mayo cohort of patients. Subsequent multivariate analysis showed that $5 \mathrm{FU}$ AUC and $\mathrm{T}_{1 / 2}$ were the primary pharmacokinetic contributors to toxicity in this cohort. These observations compare favourably with other 5FU pharmacokinetic studies in CRC patients (Gamelin et al, 1996). In order to identify possible pretreatment factors that may substitute for these 5FU pharmacokinetic parameters, we examined uracil metabolism as a surrogate marker for $5 \mathrm{FU}$ metabolism. The results clearly showed a correlation between baseline concentrations of $\mathrm{UH}_{2}$ and $5 \mathrm{FUH}_{2}$, AUC providing the opportunity to assess actual enzymatic activity immediately before chemotherapy treatment. Indeed $\mathrm{UH}_{2} / \mathrm{U}$ ratio has been used to predict patients with impaired DPD activity (Gamelin et al, 1999; Yang et al, 2011). According to these studies, a $\mathrm{UH}_{2} / \mathrm{U}$ ratio of $>2.0$ (Gamelin et al, 1999) or $>0.5$ (Yang et al, 2011) would be indicative of normal DPD function. All of the patients in our study cohort presented with a $\mathrm{UH}_{2} / \mathrm{U}>2.0$, thus none presented with DPD deficiency, indeed complete DPD depletion is a relatively rare event in the general population (Etienne et al, 1994). Not surprisingly, $\mathrm{UH}_{2} / \mathrm{U}$ did not predict for clinical toxicity (Table 5); however, the strong relationship between $\mathrm{UH}_{2} / \mathrm{U}$ and $\mathrm{UH}_{2}$ with $5 \mathrm{FUH}_{2}$ validates the ongoing use of $\mathrm{UH}_{2} / \mathrm{U}$ as a surrogate marker for DPD activity as shown by other research groups.

Our results show for the first time that variability in TL may be a measure of end organ sensitivity to chemotherapy in humans. Although the actual biology underlying this mechanism remains to be determined, several lines of evidence suggest that the proliferative capacity of a cell, as measured by TL, determines its ability to effectively respond to environmental insults. Replicative strain on progenitor cell telomeres is observed in recipients of bone marrow transplants who have shorter blood cell telomeres compared with their donors (Wynn et al, 1998). We have previously shown that CD34+ progenitor cells with short TL took longer to repopulate the haematopoietic system than those with longer TL in cancer patients undergoing autologous bone marrow transplantation after high-dose chemotherapy (Lincz et al, 2004). Indeed, the relationship between TL in stem cell progenitor cells and bone marrow dysfunction has been well established (Ball et al, 1998; Du et al, 2009), and abnormally short TL have been associated with myeloproliferative disorders such as aplastic anaemia (Ball et al, 1998). It is perhaps not surprising that PBMNC TL could be used to predict haematological toxicity from 5FU. The link between PBMNC TL and the development of mucositis is less evident, but is likely to be dependent on 

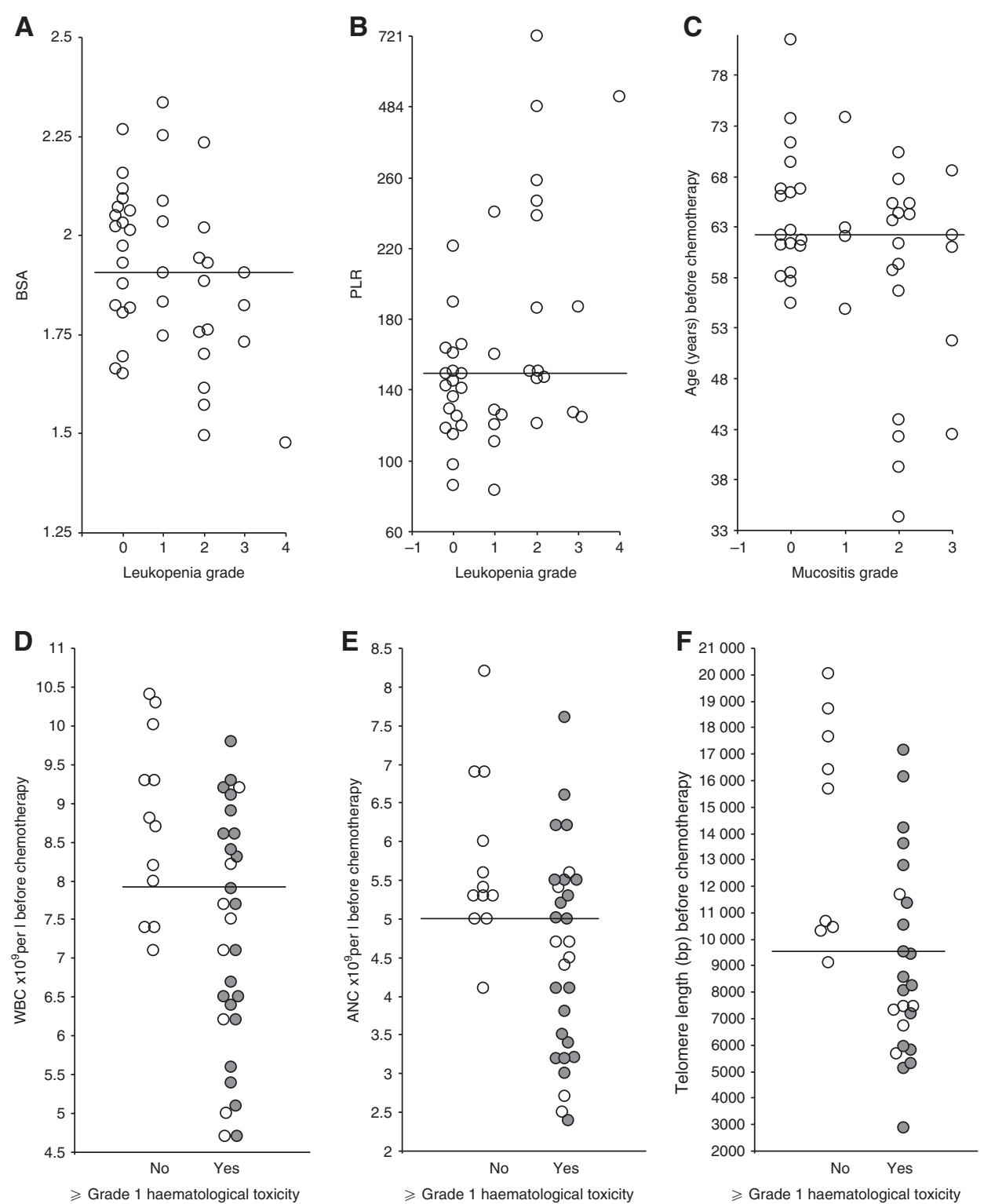

Figure I Association between 5FU-induced clinical toxicity and specific pre-treatment blood parameters in patients receiving the Mayo Schedule of chemotherapy. A smaller BSA $(P=0.0 \mathrm{I})$ and an increase in PLR $(P=0.005)$ strongly associates with the induction and severity of leukopenia $(\mathbf{A}$, B). Induction and severity of mucositis strongly associates with younger patients $(P=0.017)(\mathbf{C})$. Lower WBC $(P=0.006)$ and lower ANC $(P=0.008)$ strongly associates with induction of haematological toxicity $(\mathbf{D}, \mathbf{E})$. Short TL in PBMNCs strongly associates $(P=0.003)$ with induction of haematological toxicity $(\mathbf{F})$. Haematological toxicity is defined as grade I or greater leukopenia and/or neutropenia (shaded circles represent grades 3 and 4). The solid bar represents the median value.

production of blood cells for adequate wound healing. Indeed, this process is severely compromised via a delay in reepithialisation in telomerase-deficient mice presenting with severely short TL (Rudolph et al, 1999). Moreover, in an aging cohort of telomerasedeficient mice (mTR $-/-$ ), TL shortening was associated with reduced capacity to respond to stresses such as wound healing and 5FU-induced haematopoietic ablation (Rudolph et al, 1999). However, we cannot exclude the possibility that the mucosal cells may also have had short telomeres, increasing their susceptibility to the chemotherapy insult.

It is generally the case that younger people possess longer telomeres than older people (Hastie et al, 1990; Lindsey et al, 1991; Slagboom et al, 1994; Vaziri et al, 1994; Ball et al, 1998; Frenck et al, 1998; Wynn et al, 1998); however, it is now evident that telomere attrition is a combination of continued cell replication and oxidative damage (Blackburn, 2005; Epel, 2009). Thus, lifestyle and oxidative status significantly contribute to telomere dynamics, as evidenced by the lack of association between TL and age in our study cohort. This is further substantiated by the existence of both age and TL in the model of mucositis, indicating that the two measurements are independent and refer to different biological processes. Indeed, younger patients in our cohort were most likely to present with mucositis. Previous studies looking at age and mucositis risk have shown mixed results, with the very young and the very old both at a greater risk (Barasch and Peterson, 2003; Keefe, 2006). The increased turnover of the mucosal lining of younger patients may be the underlying cause of their sensitivity (Barasch and Peterson, 2003), whereas the cause in the very elderly is not known.

Toxicity was also strongly predicted by PLR, a known marker of SIR. This and other markers of SIR such as C-reactive protein (CRP), Glasgow Prognostic Score (combining albumin and CRP) 
Predicting 5FU-induced toxicity in colorectal cancer

Table 5 Multivariate analysis of toxicity vs independent variables in CRC patients receiving $5 F U$ treatment. The posttreatment model utilised 5FU PK variables while the predictive model utilised $U$ variables.

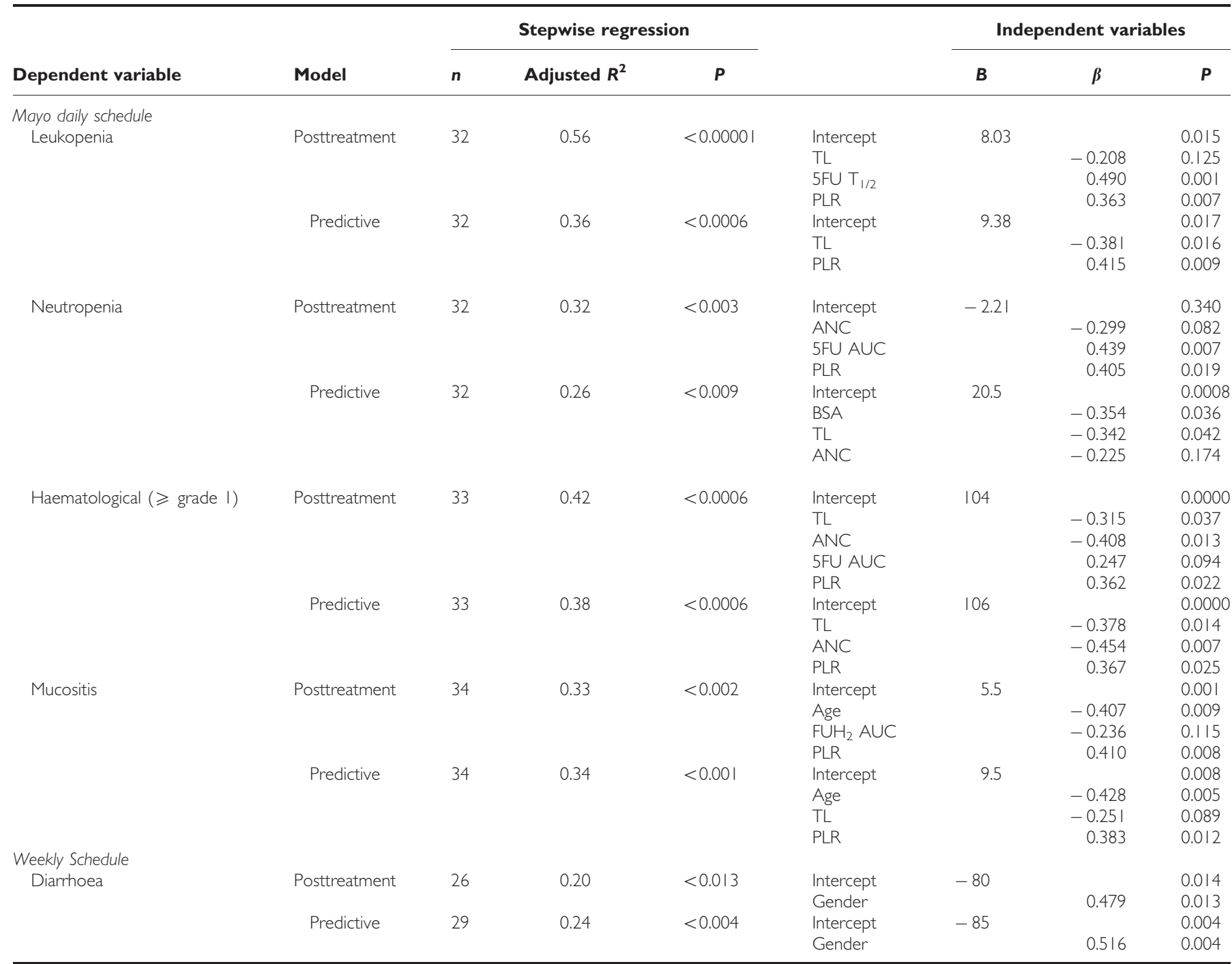

Abbreviations: $5 \mathrm{FU}=5$-fluorouracil; $\mathrm{ANC}=$ absolute neutrophil count; $\mathrm{AUC}=$ area under the curve; $\mathrm{B}=$ intercept regression coefficient; $\beta=$ standardised regression coefficient; $\mathrm{BSA}=$ body surface area; $\mathrm{FUH}_{2}=$ dihydrofluorouracil; $\mathrm{PK}=$ pharmacokinetics; $\mathrm{PLR}=$ platelet lymphocyte ratio; $\mathrm{TL}=$ telomere length; $U=$ uracil; $U \mathrm{H}_{2}=$ dihydrouracil.

and NLR (Chua et al, 2011a) have shown prognostic significance for various malignancies, including CRC, when employed in the preoperative setting. However, only one other study has examined the relationship of PLR to chemotherapy-induced toxicity (Arrieta et al, 2010). Generally, a PLR value of $\geqslant 150$ and a NLR value of $\geqslant 5$ represent a SIR (Arrieta et al, 2010; Chua et al, 2011a). In our cohort of patients 18 of $41(44 \%)$ had a PLR $\geqslant 150$, of which 12 presented with grade 1 or higher leukopenia (Figure 1), whereas NLR did not predict for toxicity; indeed only 5 of 41 (12\%) patients had a NLR $\geqslant 5$. In two other CRC cohorts the proportion of patients with an NLR >5 was reported to be $29 \%$ and $31 \%$ (Chua et al, 2011a) and predicted for PFS and OS; however, these cohorts represented metastatic disease, suggesting that the incidence of NLR $>5$ may increase with disease progression. Unfortunately, PLR was not studied in these advanced CRC studies, and the lack of follow-up survival data in the current study make it impossible to draw any conclusions. The underlying cause and development of SIR in oncology patients is unclear. Some suggestions included tumour hypoxia-necrosis and local tissue damage causing disturbances in neuroendocrine metabolism, interleukine synthesis and acute phase protein production. However, the present cohort of patients was assessed in the adjuvant setting, precluding tumour-associated effects. The link between SIR and clinical toxicity is also unclear. Increased toxicity may be caused by a reduction in chemotherapy metabolism which would raise plasma 5FU levels. Indeed, acute phase reactants produced during SIR are known to alter the liver function and have been associated with increased plasma albumin and BSA (Arrieta et al, 2010). Although a similar phenomenon was observed in our patient cohort, there was no association between PLR and 5FU PK variables, suggesting that any decrease in liver function was not sufficient to impact on $5 \mathrm{FU}$ metabolism or plasma levels.

In conclusion, we have shown that measures of $U$ metabolism can predict for 5FU metabolism, and that peripheral blood mononuclear cell TL and PLR were identified as strong predictors of 5FU-induced toxicity. Although the results provide clear evidence to suggest that preclinical assessment of TL and simple blood cell analysis should be included in standard pretreatment 
blood screening in CRC patients preparing for chemotherapy, it is also important to validate these findings in other CRC chemotherapy regimens. Such screening would identify those patients most likely to experience haematological toxicity and mucositis; providing crucial information for optimising patient care. Indeed many elderly patients forego chemotherapy and many clinicians withhold chemotherapy on the belief that age predicts for poor clinical outcome and increased toxicity. Our study refutes this and

\section{REFERENCES}

Ackland SP, Garg MB, Dunstan RH (1997) Simultaneous determination of dihydroflurouracil and 5-fluorouracil in plasma by high-performance liquid chromatography. Anal Biochem 246: 79-85

Arrieta O, Michel Ortega RM, Villanueva-Rodríguez G, Serna-Thomé M, Flores-Estrada D, Diaz-Romero C, Rodríguez CM, Martínez L, SánchezLara K (2010) Association of nutritional status and serum albumin levels with development of toxicity in patients with advanced non-small cell lung cancer treated with paclitaxel-cisplatin chemotherapy: a prospective study. BMC Cancer 10: 50

Ball SE, Gibson FM, Rizzo S, Tooze JA, Marsh JCW, Gordon-Smith EC (1998) Progressive telomere shortening in aplastic anemia. Blood 91: 3582-3592

Barasch A, Peterson DE (2003) Risk factors for ulcerative oral mucositis in cancer patients: unanswered questions. Oral Oncol 39: 91-100

Blackburn EH (2005) Telomeres and telomerase: their mechanisms of action and the effects of altering their functions. FEBS Lett 579: 859-862

Chua W, Charles KA, Baracos VE, Clarke SJ (2011a) Neutrophil/lymphocyte ratio predicts chemotherapy outcomes in patients with advanced colorectal cancer. Br J Cancer 104: 1288-1295

Chua W, Kho PS, Moore MM, Charles KA, Clarke SJ (2011b) Clinical, laboratory and molecular factors predicting chemotherapy efficacy and toxicity in colorectal cancer. Crit Rev Oncol Hematol 79: 224-250

Ciccolini J, Mercier C, Evrard A, Dahan L, Boyer JC, Duffaud F, Richard K, Blanquicett C, Milano G, Blesius A, Durand A, Seitz JF, Favre R, Lacarelle $B$ (2006) A rapid and inexpensive method for anticipating severe toxicity to fluorouracil and fluorouracil-based chemotherapy. Ther Drug Monit 28: $678-685$

Diasio RB, Beavers TL, Carpenter JT (1988) Familial deficiency of dihydropyrimidine dehydrogenase. Biochemical basis for familial pyrimidinemia and severe 5-fluorouracil-induced toxicity. J Clin Invest 81: 47-51

Du H-Y, Pumbo E, Ivanovich J, An P, Maziarz RT, Reiss UM, Chirnomas D, Shimamura A, Vlachos A, Lipton JM, Goyal RK, Goldman F, Wilson DB, Mason PJ, Bessler M (2009) TERC and TERT gene mutations in patients with bone marrow failure and the significance of telomere length measurements. Blood 113: 309-316

Epel ES (2009) Psychological and metabolic stress: a recipe for accelerated cellular aging? Hormones 8: 7-22

Etienne MC, Lagrange JL, Dassonville O, Fleming R, Thyss A, Renee N, Schneider M, Demard F, Milano G (1994) Population study of dihydropyrimidine dehydrogenase in cancer patients. J Clin Oncol 12: 2248-2253

Frenck Jr RW, Blackburn EH, Shannon KM (1998) The rate of telomere sequence loss in human leukocytes varies with age. PNAS 95: 5607-5610

Gamelin E, Boisdron-Celle M, Guerin-Meyer V, Delva R, Lortholary A, Genevieve F, Larra F, Ifrah N, Robert J (1999) Correlation between uracil and dihydrouracil plasma ratio, fluorouracil (5-FU) pharmacokinetic parameters, and tolerance in patients with advanced colorectal cancer: a potential interest for predicting 5-FU toxicity and determining optimal 5-FU dosage. J Clin Oncol 17: 1105-1105

Gamelin E, Danquechin-Dorval EM, Dumesnil YF, Maillart PJ, Goudier MJ, Burtin PC, Delva RG, Lortholary AH, Gesta PH, Larra FG (1996) Relationship between 5-fluorouracil (5-FU) dose intensity and therapeutic response in patients with advanced colorectal cancer receiving infusional therapy containing 5-FU. Cancer 77: 441-451

Garg MB, Sevester JC, Sakoff JA, Ackland SP (2002) Simple liquid chromatographic method for the determination of uracil and dihydrouracil plasma levels: a potential pretreatment predictor of 5-fluorouracil toxicity. J Chromatogr B 774: 223-230 provides a simple means to determine patient suitability for chemotherapy.

\section{ACKNOWLEDGEMENTS}

We are grateful for financial support from the Calvary Mater Newcastle Hospital and the University of Newcastle, NSW Australia.
Goldberg JA, Kerr DJ, Willmott N, McKillop JH, McArdle CS (1988) Pharmacokinetics and pharmacodynamics of locoregional 5-fluorouracil (5FU) in advanced colorectal liver metastases. Br J Cancer 57: 186-189

Gurney HP, Ackland SP, Gebski V, Farrell G (1998) Factors affecting epirubicin pharmacokinetics and toxicity: evidence against using bodysurface area for dose calculation. J Clin Oncol 16: 2299-2304

Gusella M, Frigo AC, Bolzonella C, Marinelli R, Barile C, Bononi A, Crepaldi G, Menon D, Stievano L, Toso S, Pasini F, Ferrazzi E, Padrini R (2009) Predictors of survival and toxicity in patients on adjuvant therapy with 5-fluorouracil for colorectal cancer. $\mathrm{Br} \mathrm{J}$ Cancer 100: $1549-1557$

Hastie ND, Dempster M, Dunlop MG, Thompson AM, Green DK, Allshire RC (1990) Telomere reduction in human colorectal carcinoma and with ageing. Nature 346: 866-868

Keefe DMK (2006) Mucositis management in patients with cancer. Support Cancer Ther 3: 154-157

Lincz LF, Scorgie FE, Sakoff JA, Fagan KA, Ackland SP, Enno A (2004) Telomere length predicts neutrophil recovery in the absence of G-CSF after autologous peripheral blood stem cell transplantation. Bone Marrow Transplant 34: 439-445

Lindsey J, McGill NI, Lindsey LA, Green DK, Cooke HJ (1991) In vivo loss of telomeric repeats with age in humans. Mutat Res 256: 45-48

Lu Z, Zhang R, Diasio RB (1993) Dihydropyrimidine dehydrogenase activity in human peripheral blood mononuclear cells and liver: population characteristics, newly identified deficient patients, and clinical implication in 5-fluorouracil chemotherapy. Cancer Res 53: 5433-5438

Milano G, Etienne MC, Renee N, Thyss A, Schneider M, Ramaioli A, Demard F (1994) Relationship between fluorouracil systemic exposure and tumour response and patient survival. J Clin Oncol 12: 1291-1295

Miller SA, Dykes DD, Polesky HF (1988) A simple salting out procedure for extracting DNA from human nucleated cells. Nucleic Acids Res 16(3): 1215

Patel K, Anthoney DA, Crellin AM, Sebag-Montefiore D, Messruther J, Seymour MT (2004) Weekly 5-fluorouracil and leucovorin: achieving lower toxicity with higher dose-intensity in adjuvant chemotherapy after colorectal cancer resection. Ann Oncol 15: 568-573

Rhyu MS (1995) Telomeres, Telomerase, and Immortality. J Natl Cancer Inst 87: 884-894

Rudolph KL, Chang S, Lee H-W, Blasco M, Gottlieb GJ, Greider C, DePinho RA (1999) Longevity, stress response, and cancer in aging telomerasedeficient mice. Cell 96: 701-712

Sakoff JA, De Waal E, Garg MB, Denham J, Scorgie FE, Enno A, Lincz LF, Ackland SP (2002) Telomere length in haemopoietic stem cells can be determined from that of mononuclear blood cells or whole blood. Leuk Lymphoma 43: 2017-2020

Slagboom PE, Droog S, Boomsma DI (1994) Genetic determination of telomere size in humans: a twin study of three age groups. Am J Hum Genet 55: 866-869

Sommadossi JP, Gewirtz DA, Diasio RB, Aubert C, Cano JP, Goldman ID (1982) Rapid catabolism of 5-fluorouracil in freshly isolated rat hepatocytes as analyzed by high performance liquid chromatography. J Biol Chem 257: 8171-8176

Tsalic M, Bar-Sela G, Beny A, Visel B, Haim N (2003) Severe toxicity related to the 5-fluorouracil/leucovorin combination (The Mayo Clinic Regimen). Am J Clin Oncol 26: 103-106

Van Kuilenburg AB, Vreken P, Abeling NG, Bakker HD, Meinsma R, van, Lenthe H, De Abreu RA, Smeitink JA, Kayserili H, Apak MY, Christensen E, Holopainen I, Pulkki K, Riva D, Botteon G, Holme E, Tulinius M, Kleijer WJ, Beemer FA, Duran M, Niezen-Koning KE, Smit GP, Jakobs C, Smit LM, van Gennip AH (1999) Genotype and phenotype in patients 
with dihydropyrimidine dehydrogenase deficiency. [Review] [72 refs]. Hum Genet 104: 1-9

Vaziri H, Dragowska W, Allsopp RC, Thomas TE, Harley CB, Lansdorp PM (1994) Evidence for a mitotic clock in human hematopoietic stem-cells loss of telomeric DNA with age. PNAS 91: 9857-9860

Vokes EE, Mick R, Kies MS, Dolan E, Malone D, Athanasiadis I, Haraf DJ, Kozloff M, Weichselbaum RR, Ratain MJ (1996) Pharmacodynamics of fluorouracil-based induction chemotherapy in advanced head and neck cancer. J Clin Oncol 14: 1663-1671
Wynn RF, Cross MA, Hatton C, Will AM, Lashford LS, Dexter TM, Testa NG (1998) Accelerated telomere shortening in young recipients of allogeneic bone-marrow transplants. Lancet 351: 178-181

Yang CG, Ciccolini J, Blesius A, Dahan L, Bagarry-L D, Brunet C, Varoquaux A, Frances N, Marouani H, Giovanni A, Ferri-Dessens R-M, Chefrour M, Favre R, Duffaund F, Seitz J-F, Zanaret M, Lacarelle B, Mercier C (2011) DPD-based adaptive dosing of 5FU in patients with head and neck cancer: impact on treatment efficacy and toxicity. Cancer Chemother Pharmacol 67: 49-56

This work is published under the standard license to publish agreement. After 12 months the work will become freely available and the license terms will switch to a Creative Commons Attribution-NonCommercial-Share Alike 3.0 Unported License. 